\title{
Role of oxidative stress in hearing impairment in patients with type two diabetes mellitus - CORRIGENDUM
}

\author{
I ALADAG, A EYIBILEN, M GÜVEN, O ATIS, Ü ERKORKMAZ
}

doi: 10.1017/S0022215109004502, Published by Cambridge University Press, February 2009, pages 957-963.

In the published article Aladag et al. (2009), ${ }^{1}$ one of the authors' names was misspelled on submission. The fifth author was listed as Erkokmaz, $\ddot{U}$ and this should have read Erkorkmaz, Ü. The authors apologise for this error.

Reference

1 Aladag I, Eyibilen A, Güven M, Atis O, Erkokmaz Ü. Role of oxidative stress in hearing impairment in patients with type two diabetes mellitus. J Laryngol Otol. 2009;123:957-963 